\title{
An Analytical View to Environmental Quality of Life in the European Union Countries
}

\author{
Emília Huttmanová ${ }^{1}$, Roman Novotný ${ }^{1}$ and Tomáš Valentiny ${ }^{1}$
}

\begin{abstract}
Quality of life and health is very closely linked to the environmental quality. However, the environmental quality is not only perceived as a determinant of quality of life, but it is an internal part of (sustainable) development, in terms of the green growth concept, at these days. The concept of green growth is one of the newer ways to ensure economic and social development in the context of sustainable development. Economic and social development, as well as ensuring and preserving the environmental quality, has its important place in the green growth concept. Green growth requires a new view on management of economic and social development. This article is focused on the evaluation of interregional disparities in selected areas of sustainable development. The aim of the paper is to evaluate the environmental quality of life in European Union countries using the selected indicators of green growth in the context of sustainable development.
\end{abstract}

Keywords: Environment, Quality of life, Green growth, Indicators, European Union countries

\section{Introduction}

The quality of the environment has a strong influence on people's quality of life. There are direct connections between primary elements of the environment, such as air, water and soil and quality of life and health (Banzhaf et al. 2014). As the quality of life grows, so does the demand for energy, but at the same time, increased demand for energy has many negative effects (Vavrek, Chovancová 2019). When key environmental services, such as clean air and water, drought and flood protection, soil generation and preservation, and detoxification of wastes, are disrupted, the health and well-being of society will be jeopardized and current development model is one of the main drivers of natural resource consumption (Styers et al. 2010, Fazekašová et al. 2018). As one of the most pressing challenges of our century, sustainability is a major theme of global research and political agenda for decades (Markard et al. 2012). The short-term needs of humanity must be balanced with the long-term sustainability targets. Thus, sustainable development is still a convincing concept. Brundtland's definition provides two clear criteria for sustainable development that are also applicable to sustainable consumption. An economy is sustainable only if it simultaneously meets the human needs, especially the basic needs of the poor around the world, and accepts the limitations imposed by the need to preserve the environment's ability to meet present and future needs (WCED 1987). It is such development of human society that harmonizes economic and social progress, while preserving the full value of the environment. It is important to quantify for comparative purposes as well as to assess environmental changes at different levels (Adamišin, Vavrek 2014). Sustainable development is a fundamental and overarching goal of the European Union, enshrined in its Treaty. Measuring progress towards 
sustainable development is an integral part of the EU's Sustainable Development Strategy and it is important to regularly develop monitoring reports based on a set of EU Sustainable Development Indicators. Eurostat has a similar role for example and publishes a report every 2 years (Kurkowiak et al. 2015). The present combination of environmental, economic and social goals of sustainable development has proved extremely challenging to implement and its partly due to the different interpretations and applications of sustainability. Various sustainability concepts are proposed for research, policy-making and private governance (D'Amato et al. 2017). The most well-known paths of development and sustainability at the global level today include the circular economy and the green economy (EAA 2013, EC 2015).

The idea of a circular economy means that the value and usefulness of products are extended, and that waste from production and consumption is used as secondary resources, promising solutions and common benefits for a range of economic and environmental issues (Kirchherr et al. 2017, Winans et al. 2017) . Thus the concept of circular economy has gained increasing attention from policy makers, industry and academia. In 2015, the European Commission adopted a strengthened circular economy package to maintain the value of products, materials and resources in the economy as long as possible and to minimize waste generation as a fundamental contribution to the European Union efforts to develop a sustainable, low-carbon and resource-efficient economy and a competitive economy (EC 2017). There is a rapidly evolving debate on definitions, limitations and contributions to the sustainability agenda and a need for indicators to assess the effectiveness of circular economy measures at larger scales. For example, Mayer et al. (2019) innovatively linked Eurostat datasets in a fully consistent and mass-balanced way in order to achieve a systematic monitoring of resource use, waste, and recycling through the socioeconomic system and derived a set of indicators that measure the scale of input and output flows as well as socioeconomic and ecological loop closing.

The concept of green economy, the latest interpretation or better transformation of the sustainable development concept, is still focused on incremental improvements (United Nations 2012). It is innovative but still does not provide the radical changes (Lorek, Spangenberg 2014). A green economy or green growth concept was built by governments of mature and emerging economies, many international organizations, including the UN and actors from civil society and academia as a way to address environmental crises and the uncertainties of the global economy (Barbier 2012). The two terms are referring to a range of ideas linked to low-carbon development from the narrow frame of the eco-industry and environmentally friendly production to a redefinition of a country's entire economy (World Bank, DRC 2012). The OECD definition of green growth (2011) describes it as sustaining economic growth and development while ensuring that natural assets continue to provide the resources and environmental services that our wellbeing relies on. To achieve this, investment and innovation which will foster sustainable growth and stimulate the emergence of new economic opportunities must accelerate. Green growth is therefore seen as a way to achieve sustainable development and a green economy (Rodgers 2016). Bass (2013) claimed that the green economy refers to an economic system whose economic activities result in human welfare and social justice with added value, while at the same time 
focusing on reducing environmental risks (environmental risks such as increased carbon emissions and degradation of the environment) and environmental deficiencies (low supply of resources by the environment due to overexploitation). It is the economy that does not endanger the lives of people.

In the last decade, the green economy has proved to be an important policy framework for sustainable development in both developed and developing countries. It is an attractive framework for providing more resource efficient, less CO2 emissions, less harmful to the environment, and more socially inclusive societies. There are tensions between competing green economy discourses and a number of different definitions exist, all of which have major shortcomings. This is further complicated by various concepts of weak, transformational and strong green economy. Several important definitions focus on the transformational green economy. Economic and environmental measurement is essential to enable and monitor this transformation (Georgeson et al. 2017). Today, the concepts and frameworks of the green economy have influenced discourse and policy in many countries, these include the UK, France and China with a stronger focus on growth (Bailey, Caprotti 2014), several countries in Africa (such as Rwanda, Morocco, Ethiopia, Senegal and South Africa) with emphasis on its ability to provide transformations that skip current high-pollution development paradigm (United Nations Environment Programme 2015). The feedback in this process of green growth means that we need to carefully analyze each step and understand the interactions. Although goals influence decisions on measurement, targets and indicators, the availability of data and the types of indicators considered desirable or feasible can affect both decisions about goals and the nature of progress towards those goals, often with significant unintended consequences (Georgeson et al. 2017). Among the best-known measurement approaches are The Green Growth Monitoring Framework and Green Economy Indicators for Policy-Making (OECD 2011, UNEP 2014).

\section{Material and Methods}

The aim of this paper is to determine the internal links between the indicators and their impact on the development of quality of life (in the context of health) within the countries of the European area in the 21 st century. In the paper, we will consider three basic areas of factors affecting the quality of life, which are the environment, economic development and the social aspect.

As part of the concept of quality of life (in the context of health), we will consider the approach used within the EU countries. Based on Dasgupta \& Weale (1992) we included mortality, or more precisely life expectancy at birth, into the indicator. In addition, according to Kaplan, Anderson \& Wingard (1991), we considered gender differences in healthy life years (as an alternative to their well-years of life). Given that, according to Hennes et al. (1994), self-perceived health is a good proxy indicator for chronic diseases, we will also consider it within the framework of the model, given that this indicator belongs to this concept according to all the above authors. According to De Veer \& Bakker (1994), we also considered the effectiveness of home health care systems, where we used the self-reported unmet needs for medical examination indicator. The concept of economic development was established at the level of gross domestic product per 
capita, which is the basic indicator of economic development. Trade liberalization and trade openness have no simple and direct relationship with economic growth (Yanikkaya 2003), which has influenced the assignment of this factor to the concept of economic development. Gross fixed capital formation as a factor in the concept of economic development was considered due to the investment accelerator and multiplier. At the same time, we also considered compensation of employees per capita, which gives us the opportunity to consider domestic consumption in the economy (only proxy) and at the same time it represents the labor factor cost. The last indicator is total government expenditures, which is a proxy indicator for taxation rates across economies and also characterizes a portion of GDP. Within the environmental aspect, we have considered indicators related to environmental protection, not environmental damage. In the case of a construct representing the environment, we considered the factors of non-energy material productivity and energy intensity, which, moreover, according to Ekins et al. (2012) are related to the level of environmental taxation. At the same time, we also added the circular material use rate indicator, which in addition connects this concept with the concept of green growth (Tantau et al. 2018). Moreover, the last factor is environmental protection expenditure (regardless of source), being one of the most important factors involved. The social concept is the last to be counted in the analysis. According to Marmot (2005), poverty and income inequality are one of the basic social determinants of health, so we considered median net income and jobless households in the analyzes. According to WHO, namely Solar \& Irwin (2010), public policies in the field of social protection and, of course, health are also important, which is why health care expenditure, or social protection expenditures of government, has been added as important determinants of the latest concept. The last variable was the work life balance indicator, which, according to Haar et al. (2014) is one of the important aspects of life satisfaction, together with anxiety (i.e., mental health), which was why we considered the variable.

In the case of the relationship between the latent variables of the economic and social aspects, we have also derived its existence from previous research. Within this relationship, based on Lambert et al. (2014) we also consider linking societal well-being and net energy availability, while from the findings of Hall \& Jones (2004), we established the relationship between economic development and the amount of resources allocated to health service. The dependence of the latent variable of quality of life on the latent variable capturing the social aspect has been determined by several findings. Pacáková \& Kopecká (2018) argue that median income, or the amount of funding for healthcare, also affects (among other things) the quality of life. The last one is the relationship between work life balance and quality of life proposed by Haar et al. (2014). The indirect relationship between economic development and quality of life (through the social aspect) was determined by Diener \& Suh (1997), who argue that changing social aspects of quality of life, such as the availability of health care, or reducing mortality due to various types of disease, results from welfare growth within the economy. Considering Hashmi and Alam (2019), we have considered the relationship between economic and environmental concepts. The dependence of the quality of life on social and environmental aspects was determined by Harper et al. (1998). Based on the above, we have considered the set of indicators presented in Table 1. 
Table 1: List of variables

Variable Description

\section{Source}

Life expectancy at birth. Life expectancy at certain ages represents the mean

$L E B \quad$ number of years still to be lived by a person who has reached a certain exact age, if subjected throughout the rest of his or her life to the current mortality Eurostat conditions like age-specific probabilities of dying (years).

Healthy life years - males \& females. The indicator of healthy life years

HLY $m$ measures the number of remaining years that a person of specific age is \& HLY expected to live without any severe or moderate health problems. HLY is a Eurostat composite indicator that combines mortality data with health status data (years).

Self-perceived health. The concept is operationalized by a question on how a

$S P H \quad$ person perceives his/her health in general using one of the answer categories very good/good/ fair/ bad/ very bad. Indicator is constructed as proportion Eurostat of people answer very good \& good vs. very bad \& bad (percentage).

Self-reported unmet needs for medical examination. Person's own assessment of whether he or she needed examination or treatment for a

RUN specific type of health care, but didn't have it or didn't seek for it. EU-SILC Eurostat collects data on two types of health care services: medical care and dental care (percentage).

MOR Mortality. Standardized mortality per 100000 inhabitants (percentage of total Eurostat population).

Gross domestic product per capita. Natural logarithm of GDP at market

GDP prices, which is defined as the final result of the production activity of Eurostat resident producer units. (euro - before logarithm)

OPN Openness of economy. Index is constructed as sum of total export and total Eurostat import divided by GDP. (no unit)

Gross fixed capital formation. Indicator consists of resident producers'

FCF acquisitions, less disposals, of fixed tangible or intangible assets. This covers in particular machinery and equipment, vehicles, dwellings and other buildings ( $\%$ of GDP).

Total general government expenditure per capita. TGE is defined by list of categories: intermediate consumption, gross capital formation, compensation

TGE of employees, other taxes on production, subsidies, payable property income, current taxes on income, wealth, etc., social benefits other than social transfers in kind, capital transfers, etc. Constructed as natural logarithm (euro - before logarithm).

Compensation of employees per capita. Natural logarithm of CoE, which is defined as the total remuneration, in cash or in kind, payable by an employer

CoE to an employee in return for work done by the latter during the accounting Eurostat period. Compensation of employees consists of wages and salaries, and of employers' social contributions (euro - before logarithm). $\begin{array}{ll}\text { NMP Non-energy material productivity. Indicator is calculated as GDP generated } & \text { OECD } \\ \text { per unit of materials consumed (euro } / \mathrm{kg} \text { ). }\end{array}$

EI Energy intensity. Indicator is calculated as unit of consumed energy per GDP Eurostat (toe/euro).

The circular material use rate. Indicator measures the share of material

CMU recovered and fed back into the economy in overall material use (percentage). Eurostat 


\begin{tabular}{|c|c|}
\hline EPE & $\begin{array}{l}\text { Environmental protection expenditure per capita. Indicator is logarithm of } \\
\text { EPE, which is defined as the money spent on all purposeful activities directly } \\
\text { aimed at the prevention, reduction and elimination of pollution or any other } \\
\text { degradation of the environment. It includes environmental investments, } \\
\text { environmental current expenditure and environmental subsidies/transfers } \\
\text { (euro - before logarithm). }\end{array}$ \\
\hline$M N I$ & $\begin{array}{l}\text { Median net income. Value represents amount of money (at most) earned by Eurostat } \\
50 \% \text { of population (euro). }\end{array}$ \\
\hline SPE & $\begin{array}{l}\text { Social protection expenditures of government. Indicator is constructed as } \\
\text { proportion of social protection expenditures to total expenditures Eurostat } \\
\text { (percentage). }\end{array}$ \\
\hline $\mathrm{HCE}$ & $\begin{array}{l}\text { Health expenditures per capita. Indicator is characterised as natural logarithm Eurostat } \\
\text { of health expenditures per capita (euro - before logarithm). }\end{array}$ \\
\hline$J L H$ & $\begin{array}{l}\text { Jobless households. Proportion of households where no member is in } \\
\text { employment, i.e. all members are either unemployed or inactive to total Eurostat } \\
\text { number of households (percentage). }\end{array}$ \\
\hline$W L B$ & $\begin{array}{l}\text { Work life balance. Indicator is defined as numbers of hours worked per week } \\
\text { to total disposable hours per week (percentage). }\end{array}$ \\
\hline
\end{tabular}

Source: own processing

The data were longitudinal, as they were collected for 28 countries during the years 20002017. However, only 132 of observations from the total number of observations (504) was usable due to a lack of data. For the same reason, a country-specific factor could not be considered (only 3 observations were applicable for some countries). The covariance based structural equation model (CB-SEM) (Jöreskog \& Sörbom 1982, Bollen 1989) was used to determine the above relationships within the four constructs considered. The model itself is defined by the following set of equations:

$$
\begin{aligned}
& Q o L_{i t}=\gamma_{11} L E B_{i t}+\gamma_{12} H L Y_{-} m_{i t}+\gamma_{13} H L Y_{-} f_{i t}+\gamma_{14} S P H_{i t}+\gamma_{15} R U N_{i t}+\gamma_{16} M O R_{i t} \\
& E C o_{i t}=\gamma_{21} G D P_{i t}+\gamma_{22} O P N_{i t}+\gamma_{23} F C F_{i t}+\gamma_{24} T G E_{i t}+\gamma_{25} C_{o E} E_{i t} \\
& E n v_{i t}=\gamma_{31} N M P_{i t}+\gamma_{32} E I_{i t}+\gamma_{33} C M U_{i t}+\gamma_{34} E P E_{i t} \\
& S_{\text {Ooc }}=\gamma_{41} M N I_{i t}+\gamma_{42} S P E_{i t}+\gamma_{43} H C E_{i t}+\gamma_{44} J L H_{i t}+\gamma_{45} W L B_{i t} \\
& E n v_{i t}=\beta_{10}+\beta_{11} E_{c o}+\beta_{12} \text { Soc }_{i t} \\
& \text { Soc }_{i t}=\beta_{20}+\beta_{21} \text { Eco }_{i t} \quad \& \quad Q o L_{i t}=\beta_{30}+\beta_{31} \text { Soc }_{i t}+\beta_{32} E_{\text {Env }} \text { it }
\end{aligned}
$$

, where QoL, Eco, Env and Soc are latent variables as a result of confirmatory factor analysis, with $\gamma 1$ being set to 1 in all cases (since they are reference factors). The maximum likelihood estimator was used to determine the parameters of the regression equations $(\beta)$.

The statistical program $\mathrm{R}$ (v3.4.3) was used to process the data through the above analysis, specifically its extension RStudio (v1.1.442).

\section{Results and Discussion}

Creation of basic concepts of sustainable development, green growth or relations between them through CB-SEM is presented in Table 2. 
Table 2: Results of CB-SEM model

\begin{tabular}{|c|c|c|c|c|c|c|}
\hline \multicolumn{7}{|c|}{ Latent Variables: } \\
\hline & Estimate & Std.Err & z-value & $P(>|z|)$ & Std.lv & Std.all \\
\hline \multicolumn{7}{|l|}{ QoL } \\
\hline$L E B$ & 1.000 & & & & 2.317 & 0.880 \\
\hline$H L Y \_m$ & 1.379 & 0.135 & 10.211 & 0.000 & 3.196 & 0.730 \\
\hline$H L Y_{-} f$ & 0.895 & 0.146 & 6.112 & 0.000 & 2.074 & 0.499 \\
\hline$S P \vec{H}$ & 1.001 & 0.081 & 12.428 & 0.000 & 2.319 & 0.819 \\
\hline RUN & -0.727 & 0.148 & -4.897 & 0.000 & -1.684 & -0.413 \\
\hline MOR & -0.075 & 0.005 & -15.584 & 0.000 & -0.173 & -0.918 \\
\hline \multicolumn{7}{|l|}{ Eco } \\
\hline$G D P$ & 1.000 & & & & 0.571 & 0.988 \\
\hline$O P N$ & 0.189 & 0.107 & 1.769 & 0.077 & 0.108 & 0.153 \\
\hline FCF & 5.051 & 0.562 & 8.992 & 0.000 & 2.883 & 0.620 \\
\hline TGE & 1.105 & 0.021 & 53.642 & 0.000 & 0.631 & 0.989 \\
\hline $\mathrm{CoE}$ & 1.117 & 0.022 & 51.067 & 0.000 & 0.638 & 0.987 \\
\hline \multicolumn{7}{|l|}{ Env } \\
\hline$N M P$ & 1.000 & & & & 0.096 & 0.200 \\
\hline EI & 2.719 & 0.971 & 2.800 & 0.005 & 0.262 & 0.719 \\
\hline$C M U$ & 0.256 & 0.100 & 2.564 & 0.010 & 0.025 & 0.376 \\
\hline EPE & 4.762 & 1.771 & 2.689 & 0.007 & 0.459 & 1.138 \\
\hline \multicolumn{7}{|l|}{ Soc } \\
\hline$M N I$ & 1.000 & & & & 0.633 & 0.992 \\
\hline SPE & 4.800 & 0.387 & 12.409 & 0.000 & 3.037 & 0.738 \\
\hline $\mathrm{HCE}$ & 1.118 & 0.016 & 69.639 & 0.000 & 0.708 & 0.994 \\
\hline$J L H$ & -0.013 & 0.005 & -2.811 & 0.005 & -0.008 & -0.238 \\
\hline$W L B$ & -1.611 & 0.159 & -10.118 & 0.000 & -1.019 & -0.664 \\
\hline \multicolumn{7}{|c|}{ Regressions: } \\
\hline & Estimate & Std.Err & z-value & $P(>|z|)$ & Std.lv & Std.all \\
\hline
\end{tabular}

\begin{tabular}{|c|c|c|c|c|c|c|}
\hline \multicolumn{7}{|l|}{ Env } \\
\hline$E c o$ & 0.630 & 0.280 & 2.246 & 0.025 & 3.727 & 3.727 \\
\hline Soc & -0.531 & 0.240 & -2.212 & 0.027 & -3.484 & -3.484 \\
\hline \multicolumn{7}{|l|}{ Soc $\sim$} \\
\hline Eco & 1.099 & 0.023 & 47.996 & 0.000 & 0.991 & 0.991 \\
\hline \multicolumn{7}{|l|}{ QoL } \\
\hline Soc & 3.105 & 0.225 & 13.803 & 0.000 & 0.848 & 0.848 \\
\hline Env & 2.719 & 1.352 & 2.011 & 0.044 & 0.113 & 0.113 \\
\hline \multicolumn{7}{|c|}{ Variances: } \\
\hline & Estimate & Std.Err & z-value & $\mathbf{P}(>|\mathrm{z}|)$ & Std.lv & Std.all \\
\hline.$L E B$ & 1.567 & 0.249 & 6.304 & 0.000 & 1.567 & 0.226 \\
\hline .HLY_m & 8.970 & 1.190 & 7.537 & 0.000 & 8.970 & 0.468 \\
\hline.$H L Y_{-} f$ & 12.959 & 1.629 & 7.954 & 0.000 & 12.959 & 0.751 \\
\hline.$S P H$ & 2.633 & 0.373 & 7.058 & 0.000 & 2.633 & 0.329 \\
\hline .RUN & 13.803 & 1.721 & 8.019 & 0.000 & 13.803 & 0.830 \\
\hline .MOR & 0.006 & 0.001 & 5.274 & 0.000 & 0.006 & 0.157 \\
\hline.$G D P$ & 0.008 & 0.001 & 6.197 & 0.000 & 0.008 & 0.023 \\
\hline.$O P N$ & 0.487 & 0.060 & 8.123 & 0.000 & 0.487 & 0.977 \\
\hline.$F C F$ & 13.301 & 1.643 & 8.097 & 0.000 & 13.301 & 0.615 \\
\hline .TGE & 0.009 & 0.001 & 6.002 & 0.000 & 0.009 & 0.021 \\
\hline
\end{tabular}




\begin{tabular}{|lcccccc}
. CoE & 0.011 & 0.002 & 6.397 & 0.000 & 0.011 & 0.026 \\
.$N M P$ & 0.223 & 0.027 & 8.224 & 0.000 & 0.223 & 0.960 \\
.$E I$ & 0.064 & 0.010 & 6.623 & 0.000 & 0.064 & 0.483 \\
.$C M U$ & 0.004 & 0.000 & 8.330 & 0.000 & 0.004 & 0.859 \\
.$E P E$ & -0.048 & 0.019 & -2.472 & 0.013 & -0.048 & -0.294 \\
.$M N I$ & 0.006 & 0.001 & 5.307 & 0.000 & 0.006 & 0.015 \\
.$S P E$ & 7.726 & 0.956 & 8.078 & 0.000 & 7.726 & 0.456 \\
.$H C E$ & 0.006 & 0.001 & 4.323 & 0.000 & 0.006 & 0.011 \\
.$J L H$ & 0.001 & 0.000 & 8.122 & 0.000 & 0.001 & 0.943 \\
.$W L B$ & 1.317 & 0.163 & 8.093 & 0.000 & 1.317 & 0.559 \\
. QoL & 1.220 & 0.230 & 5.293 & 0.000 & 0.227 & 0.227 \\
. Eco & 0.326 & 0.041 & 7.936 & 0.000 & 1.000 & 1.000 \\
. Env & 0.007 & 0.005 & 1.394 & 0.163 & 0.720 & 0.720 \\
.Soc & 0.007 & 0.002 & 4.263 & 0.000 & 0.017 & 0.017 \\
\hline P-value (Chi-square) & 0.000 & AIC & 3877.148 & BIC & 4006.874 \\
\hline
\end{tabular}

Source: own processing

As part of the confirmatory factor analysis of health-related quality of life (QoL) indicators, life expectancy at birth $(L E B)$ was used as the reference (at the same time creating scale) and thus its weight was set to 1, with almost equal weight being attributed to self-perceived health $(S P H)$ factor, which expresses the ratio of people perceiving their health as good (or better) and people perceiving it as bad. Significant factor loading for healthy years of life in men (HLY_m) results from the fact that men have a shorter life expectancy than women $\left(H L Y \_f\right)$ due to the fact that the reference factor is $L E B$. The last two factors achieve the expected negative effect. The first capturing selfreported unmet needs for medical examination (RUN) also has a more pronounced (than previous) impact on the formation of the latent variable capturing the QoL construct. However, the mortality factor $(M O R)$ records a change in the QoL construct only at the marginal level, which is related to the analyzed region (EU) where the level of healthcare provision (and its quality) is at a relatively higher level.

The following concept, which was developed through the built model, was economic development $(E c o)$, consisting of five factors where the natural logarithm of gross domestic product per capita (GDP) acts as a scaling factor. The economic openness Index $(O P N)$ positively contributes to the construction of the latent economic component of the model, since it is the openness that leads to a more efficient allocation of resources and increased consumption (as it provides supply for products that the economy is unable or unwilling to produce). In addition, we have considered the concept of investment by companies and organizations $(F C F)$, which have a positive acceleration and multiplicative effect, which has been confirmed by the relatively strong contribution of this factor to the creation of a latent variable. The overall government expenditure factor (TGE), which is one of the ways to support production (e.g. through investment), is also beneficial, while at the same time it is helping to reduce inequalities between people and allocate capital to some extent. The last of the factors considered is the component representing the country's domestic consumption, which is based on the income level. Instead of the net wage, the cost of employment $(\mathrm{CoE})$ was used in this case, including taxes and contributions to social and health funds, which also represent 
the total labor cost for employers.

The third concept considered within the compiled model is the environment, where nonenergy material productivity $(N M P)$ is the reference factor. The most significant factor loading is recorded in the case of environmental protection expenditure (EPE), which is one of the main tools in reducing externalities in the markets. Similarly, energy intensity (EI) has a significant impact, which is directly related to the use of environmentallyfriendly technologies (together with a similar justification for the reference factor, it has led to the abstraction of the variable capturing the degree of innovation and patents focused on the environment) and the more efficient use of energy sources, composing one of the main components of expenditure (excluding labor factor costs) on inputs to production. These above-mentioned relations are confirmed by the degree of impact factor. The last factor in this latent variable is the circular material use (CMU) representing (along with EI and NMP) the concept of green growth, or more precisely circular economy. While the growth of the aforementioned factors used in this CFA analysis contributes to a significant reduction in the generation of pollution, waste and other negative impacts of human activities.

The last latent variable is constructed as a representative of the social $(S o c)$ concept in achieving a better quality of life. In this case, the reference variable was set as median net income $(M N I)$ per capita. An important factor is also the social protection expenditures of government (SPE), which through government transfers allocates capital to different parts of the population as needed (social assistance benefits, unemployment benefits, child-care allowance as a birth rate support, etc.). Health care expenditure per capita (HCE), which is one of the main factors of health-related quality of life, also has a positive impact. In addition to the aforementioned factors, we also considered the share of jobless households $(J L H)$, while in these households the quality of life is most at risk. And in the analysis, the expected results were achieved, where the growth of the share of such households is expected to reduce the latent variable of the social (and health) concept of quality of life. However, the opposite case may also affect the reduction in quality of life, i.e., excessive workload of the person. This is determined by the work life balance factor $(W L B)$, which achieves the expected negative effect of this factor loading. Thus, as the proportion of hours spent at work grows, the quality of life in social terms and to some extent (e.g. through stress) from a health perspective decreases.

Due to the above-mentioned reference factors, the individual latent variables are given by units, specifically years (QoL), euro kg-1 (Env) and euro (Eco \& Soc). In the last step of the model, we considered the direct influence of Env on QoL, direct and indirect influence of $S o c$ on $Q o L(S o c \rightarrow Q o L \& S o c \rightarrow E n v \rightarrow$ QoL $)$ and indirect influence of Eco on $Q_{o L}\left(\mathrm{E}_{\mathrm{co}} \rightarrow \mathrm{Env} \rightarrow\right.$ QoL \& $\mathrm{Eco}_{\mathrm{O} o} \rightarrow \mathrm{Soc}_{\mathrm{O}} \rightarrow$ QoL). The first regression equation determines the influence of the economic and social aspects on changes in the latent variable representing the environment (but in terms of preventing damage, not the damage itself). Based on this, we have determined the proportional relationship between the economic latent variable $(E c o)$ and the variable Env. This expected state confirms that the higher the level of production in the country, the more resources are spent on reducing the impact of human activities and more effective transformation of inputs into outputs within the economy. On the other hand, increasing social considerations (Soc) results in a reduction in the environment variable, which is related to resource 
constraints, and when a country (government, but also business) is more inclined to maintain a social concept, the amount of resources to prevent environmental damage is reduced. Another equation deals with the dependence of the social aspect on the economic, where we expect an increase in $S o c$ as economic indicators grow, which implies that an increasing amount of resources is allocated on sustainability in economic growth. If we also consider the result of the previous equation, economic growth affects the almost equally proportional increase in the level of the social concept, and any increase resulting from the synergy effect (or from the country's wealth effect) is then allocated to other issues, e.g. environment. From the last equation, we have determined that the growth of environmental (from the point of environmental protection and not environmental damage) and the social aspect (and thus also through the growth of Eco) increases the quality of life and health of the population. As the social dimension increases the population's ability to allocate more resources to their health, reducing the impact of environmental pollution on the quality of life and health is reduced by increasing environmental technology support and minimizing the impact of externalities. While both cases relate to economic growth and thus to an increase in funds.

\section{Conclusion}

Findings from model construction confirm that the growth of protectionist measures within the environmental aspect is increasing quality of life related to health. While it is important to add that the level of measures is directly related to the economic development of economies (which is based on a greater degree of pollution but also on a greater number of resources allocated to the issue), while in the case of the social aspect a negative relationship has been achieved, which lies in resource constraints. Thus, when resources are allocated to the social sphere, the number of resources for environmental protection is reduced (in relative terms). These findings are consistent with claims of Diener \& Suh (1997) that economic development has an impact on the growth of social aspects of quality of life. The almost equally proportional relationship between social and economic concepts corresponds to representation of Diener \& Diener (1995) that in almost all cases this relationship is so high that the question of whether welfare is not enough to determine the quality of life and social development is exposed. The analysis also confirmed that health-related expenditures are raising with economic growth, which reflects the findings of Hall \& Jones (2004). Our results regarding the positive energy use relationship and the social indicators of quality of life are consistent with Lambert et al. (2014). In addition, based on the results, we are able to confirm the negative relationship between work-life balance, which reflects the results suggested by Haar et al. (2014). Based on the findings of Greenhaus et al. (2003), this finding is associated with higher workloads (and the resulting increase in stress) in the observed countries. Within the overall perception of relations, the importance of all three concepts (economic, social and environmental) in view of the growth of health-related quality of life within the observed countries (EU-28) between 2000 and 2017 has been confirmed. 


\section{Acknowledgements}

This paper is supported by GAPU 45/2018 "Analytical View on the Evaluation of the Impact of Environmental Quality in Relation to the Health Quality Dimension", VEGA 1/0578/18 "A Modification of the Methodologies for the Sustainable Development Assessment", KEGA 038PU - 4/2018 "Development of the Study Program Environmental Management in the II. Degree of Study" and GAPU 39/2018 "Evaluation of the Sustainable Development Indicators in the European Area in the Context of the Agenda 2030".

\section{References}

Adamišin, P., Vavrek R. (2014). Sustainability Analysis of Selected Eastern European and South-East European Countries via Parameter of Complex Sustainability Assessment Q(i). In: Geoconference on Ecology, Economics, Education and Legislation, SGEM 2014, Volume III, Bulgaria, 399-405.

Bailey, I., Caprotti, F. (2014). The green economy: functional domains and theoretical directions of enquiry. Environment and Planning A, 46, 1, 797-813.

Banzhaf, E., de la Barrera, F., Kindler, A., Reyes-Paecke, S., Schlink, U., Welz, J., Kabisch, S. (2014). A conceptual framework for integrated analysis of environmental quality and quality of life. Ecological Indicators, 45, 664-668.

Barbier, E. B. (2012). The green economy Post Rio+20. Science, 338, 887-888.

Bass, S. (2013). Scoping a green economy. London: IIED Press.

Bollen, K. A. (1989). A new incremental fit index for general structural equation models. Sociological Methods \& Research, 17(3), 303-316.

D'Amato, D., Droste, N., Allen, B., Kettunen, M., Lähtinen, K., Korhonen, J., Leskinen, P., Matthies, B. D., Toppinen, A. (2017). Green, circular, bio economy: A comparative analysis of sustainability avenues. Journal of Cleaner Production, 168, 716-734.

Dasgupta, P., Weale, M. (1992). On measuring the quality of life. World development, 20(1), 119-131.

De Veer, A. J. E., \& De Bakker, D. H. (1994). Measuring unmet needs to assess the quality of home health care. International journal for quality in health care, 6(3), 267-274.

Diener E., Diener C. (1995). The wealth of nations revisited: Income andquality of life. Social Indicators Research, 36, 275-286.

Diener E., Suh, E. (1997). Measuring quality of life: economic, social and subjective indicators. Social Indicators Research, 40, 189-216.

EAA (2013). Towards a Green Economy in Europe - EU Environmental Policy Targets and Objectives 2010-2050, 10.2800/6337, Copenhagen, Denmark.

EC (2015). EC Closing the Loop - an EU Action Plan for the Circular Economy. Communication from the Commission to the European Parliament, the Council, the European Economic and Social Committee and the Committee of the Regions, COM/2015/0614. https://eurlex.europa.eu/legal-content/EN/TXT/?uri=CELEX\%3A52015DC0614 Accessed June 21, 2019.

EC (2017). Report from the Commission to the European Parliament, the Council, the European Economic and Social Committee and the Committee of the Regions on the implementation of the Circular Economy Action Plan. Brussels: European Commission. COM(2017) 33 final. http://ec.europa.eu/environment/circular-economy/implementation report.pdf Accessed June 21, 2019.

Ekins, P., Pollitt, H., Summerton, P., Chewpreecha, U. (2012). Increasing carbon and material productivity through environmental tax reform. Energy Policy, 42, 365-376.

Fazekašová, D., Fazekaš, J., Chovancová, J., Rovňák, M., Torma S., Vavrek R. (2018). Prírodné zdroje a ich využitie v podmienkach udržatel’ného rozvoja. Prešov: Bookman.

Georgeson, L., Maslin, M., Poessinouw, M. (2017). The global green economy: a review of concepts, definitions, measurement methodologies and their interactions. Geo: Geography and Environment, 4, 1, e00036. 
Greenhaus J.H., Collins K.M., Shaw J.D. (2003). The relation between work-family balance and quality of life. Journal of Vocational Behavior, 63, 510-531.

Haar, J. M., Russo, M., Suñe, A., Ollier-Malaterre, A. (2014). Outcomes of work-life balance on job satisfaction, life satisfaction and mental health: A study across seven cultures. Journal of Vocational Behavior, 85(3), 361-373.

Hall, R. E., \& Jones, C. I. (2007). The value of life and the rise in health spending. The Quarterly Journal of Economics, 122(1), 39-72.

Harper, A., Power, M., \& WHOQOL Group, X. (1998). Development of the World Health Organization WHOQOL-Bref quality of life assessment. Psychological Medicine, (28), 551-558.

Hashmi, R., Alam, K. (2019). Dynamic relationship among environmental regulation, innovation, CO2 emissions, population, and economic growth in OECD countries: A panel investigation. Journal of Cleaner Production.

Hennessy, C. H., Moriarty, D. G., Zack, M. M., Scherr, P. A., \& Brackbill, R. (1994). Measuring healthrelated quality of life for public health surveillance. Public health reports, 109(5), 665.

Jöreskog, K. G., Sörbom, D. (1982). Recent developments in structural equation modeling. Journal of Marketing Research, 404-416.

Kaplan R. M., Anderson J. P., Wingard D. L. (1991). Gender differences in health-related quality of life. Health Psychology, 10(2), 86.

Kirchherr, J., Reike, D., Hekkert, M. (2017). Conceptualizing the circular economy: An analysis of 114 definitions. Resources, Conservation and Recycling, 127, 221-232.

Kurkowiak, Barbara et al. (eds.) (2015). Sustainable development in the European Union. 2015 monitoring report of the EU sustainable development strategy. Eurostat Statistical books 2015 edition. Luxembourg: Publications Office of the European Union.

Lambert, J. G., Hall Ch. A. S., Balogh S., Gupta A., Arnold, M. (2014). Energy, EROI and quality of life. Energy Policy, 64(2014), 153-167.

Lorek, S., Spangenberg, J. H. (2014). Sustainable consumption within a sustainable economy-beyond green growth and green economies. Journal of cleaner production, 63, 33-44.

Markard, J., Raven, R., Truffer, B. (2012). Sustainability transitions: an emerging field of research and its prospects. Research Policy, 41, 955-967.

Marmot, M. (2005). Social determinants of health inequalities. The lancet, 365(9464), 1099-1104.

Mayer, A., Haas, W., Wiedenhofer, D., Krausmann, F., Nuss, P., Blengini, G. A. (2019). Measuring Progress towards a Circular Economy: A Monitoring Framework for Economy- wide Material Loop Closing in the EU28. Journal of Industrial Ecology, 23, 1, 62-76.

OECD (2011). Food and Agriculture, OECD Green Growth Studies. Paris: OECD Publishing. https://doi.org/10.1787/9789264107250-en Accessed June 21, 2019.

OECD (2011). Towards green growth: Monitoring progress. https://millenniumindicators.un.org/unsd /envAccounting/ceea/meetings/UNCEEA-6-11.pdf Accessed June 21, 2019.

Pacáková V., Kopecká L. (2018). Inequalities in health status depending on socio-economic situation in the European countries. Economics and Management 21, 4-20.

Rodgers, P. (2016). Is green economy achievable through championing green growth? A local government experience from Zambia. Jàmbá, 8, 3, 1-10.

Styers, D. M., Chappelka, A. H., Marzen, L. J., Somer, G. L. (2010). Developing a landcover classification to select indicators of forest ecosystem health in a rapidly urbanizing landscape. Landscape and Urban Planning, 94, 158-165.

Tantau, A., Maassen, M., Fratila, L. (2018). Models for analyzing the dependencies between indicators for a circular economy in the European Union. Sustainability, 10(7), 2141.

United Nations (2012). The future We want. In: Final Declaration of the UNCSD conference, Rio de Janeiro, June 2012. https://sustainabledevelopment.un.org/content/documents/733FutureWeWant.pdf Accessed June 21, 2019.

United Nations Environment Programme (2014). Using Indicators for Green Economy Policymaking. https://wedocs.unep.org/bitstream/handle/20.500.11822/9532/-Using\%20indicators $\% 20$ for $\% 20 \mathrm{Green} \% 20$ Economy $\% 20$ policymaking-2014IndicatorsWorkingPaper.pdP?sequence $=3$ \&isAllowed $=\mathrm{y}$ Accessed June 21, 2019. 
United Nations Environment Programme (2015). Building inclusive green economies in Africa: Experience and lessons learned 2010-2015, Nairobi. http://www.greengrowthknowledge.org/sites/default /files/downloads/resource/Building_Inclusive Green Economies In Africa UNEP.pdf Accessed June 21, 2019.

Vavrek, R., Chovancová, J. (2019). Assessment of economic and environmental energy performance of EU countries using CV-TOPSIS technique. Ecological Indicators, 106, 105519.

WCED (1987). Our Common Future: World Commission on Environment and Development. Oxford: Oxford University Press.

Winans, K., Kendall, A., Deng, H. (2017). The history and current applications of the circular economy concept. Renewable and Sustainable Energy Reviews, 68, 825-833.

World Bank, DRC (2012). China 2030: Building a Modern, Harmonious, and Creative High-income Society. The World Bank and the Development Research Center of the State Council, the People's Republic of China. Washington, DC: World Bank. https://openknowledge.worldbank.org/handle/10986/6057 Accessed June 21, 2019.

Yanikkaya, H. (2003). Trade openness and economic growth: a cross-country empirical investigation. Journal of Development economics, 72(1), 57-89. 